\title{
Towards a framework for modular service design synthesis
}

\author{
Løkkegaard, Martin; Mortensen, Niels Henrik; McAloone, Tim C.
}

\section{Published in:}

Research in Engineering Design

Link to article, DOI:

10.1007/s00163-016-0215-6

Publication date:

2016

Document Version

Peer reviewed version

Link back to DTU Orbit

\section{Citation (APA):}

Løkkegaard, M., Mortensen, N. H., \& McAloone, T. C. (2016). Towards a framework for modular service design synthesis. Research in Engineering Design, 27(3), 237-249. https://doi.org/10.1007/s00163-016-0215-6

\section{General rights}

Copyright and moral rights for the publications made accessible in the public portal are retained by the authors and/or other copyright owners and it is a condition of accessing publications that users recognise and abide by the legal requirements associated with these rights.

- Users may download and print one copy of any publication from the public portal for the purpose of private study or research.

- You may not further distribute the material or use it for any profit-making activity or commercial gain

- You may freely distribute the URL identifying the publication in the public portal 


\section{Title Page}

\section{Paper title:}

Towards a Framework for Modular Service Design Synthesis

\section{Authors}

Name: Martin Løkkegaard (corresponding author)

Department: Department of Mechanical Engineering

University/Institution: Technical University of Denmark

Town/City: Kgs. Lyngby

Country: Denmark

Phone: +45 25218120/ +45 45256046

Email:mloek@mek.dtu.dk

Name: Niels Henrik Mortensen

Department: Department of Mechanical Engineering

University/Institution: Technical University of Denmark

Town/City: Kgs. Lyngby

Country: Denmark

Name: Tim C. McAloone

Department: Department of Mechanical Engineering

University/Institution: Technical University of Denmark

Town/City: Kgs. Lyngby

Country: Denmark

\section{Biographical Details}

Martin Løkkegaard holds a M.Sc. Eng. in Design \& Innovation and is a PhD student at the Section of Engineering Design and Product Development at Department of Mechanical Engineering at the Technical University of Denmark. His current research is focused on system architecture integration for high-speed product development.

Niels Henrik Mortensen holds a PhD and a M.Sc. in Mechanical Engineering and is 
employed as a Professor at the Technical University of Denmark. He is head of section at DTU Mechanical Engineering at the Technical University of Denmark. His main research focus is procedures and methods supporting development of Product Families based on Architectures and Platforms. Currently there are 9 researchers within the field of architecture based product development.

Tim McAloone is Professor of Product/Service-Systems at the Technical University of Denmark. He works closely with Danish industry, creating new methods and models for a wide range of product development issues, such as product/service-systems, sustainable design and eco-innovation. He has many research activities, including projects such as the Innovation Consortium "PROTEUS", which focuses on the creation of product/service innovation methodologies for the Danish maritime industry, plus the UNEP Eco-Innovation manual. Tim received his $\mathrm{PhD}$ from Cranfield University in 1998, where he studied the integration of eco-design strategies into industry. His first degree is in Mechanical Engineering from Manchester Metropolitan University in 1993.

\footnotetext{
Abstract:

This paper seeks to improve the understanding of how service-based companies can benefit from developing and delivering service offerings from a standardised core of service modules, which are organised through a service architecture. Research within the field is relatively sparse and there is scope for an explicit definition of elements related to the development of modular service platforms and architectures. A study of existing literature, combined with a comprehensive case study in a global engineering consultancy, has created the basis for development and evaluation of the conceptual model for modular service design synthesis presented in this paper. The case study is based on internal documentation and a high level of interview data. Inductive research methods have been used for the analysis. The presented conceptual model defines three suggested dimensions (Market Segmentation, Service Roadmap and Service Architecture Layout) to be included in development of modular service platforms and architectures. Testing indicates a significant standardisation potential for service configuration across service families. Our understanding is
} 
that the approach can increase strategic flexibility and adaptability to changes in a quick evolving service market. The empirical part of this paper is exploratory in nature and is limited to one provider of high-end engineering consultancy services. Thus, further research will be needed to verify the aspects of the presented methodology to allow a further generalisation of our findings. Nevertheless, this paper contributes to the emerging literature on service modularity by presenting a specific operational approach for description and utilisation of modular service platforms and architectures.

\section{Keywords:}

Service Design Synthesis, Service Modularity, Modular Platforms and Architectures, Strategic Service Development, Application of Service Platforms. 


\section{Introduction}

The ever accelerating evolution of technology, changing market structures and financial challenges over the past few years have made it increasingly important for service-based companies to be able to effectively manage innovation and service delivery (Chae 2012). To sustain a competitive edge, in a market where competitors are quick to copy successes and with short life cycles, servicebusinesses have no time to rest (Chesbrough 2011). Companies often struggle to adapt quickly to market changes and to align service offerings to constantly evolving customer needs (Menor et al. 2002). To stay competitive, companies must be evolutionary and able to operate with an effective and holistic strategy, from both a short-term and a long-term perspective, which is not an easy task. This paper suggests that the key to obtaining the level of flexibility and competitiveness needed for success in service-based companies can be found in the methodology of modular platforms and architectures.

The core concept of modular product platforms and architectures, based on reuse of standard designs and commonality across product families, is well established in the production industry. A broad base of recognised literature supports the methodology and new research is constantly driving it forward. A number of pioneers exists in the field e.g. Collier (1981); Utterback \& Meyer (1993); Robertson \& Ulrich (1998). The concept has evolved over the past three decades and today some of the recognised benefits of the methodology include decreased time-to-market, decreased production cost, faster introduction of new technologies into existing production lines (Meyer \& Lehnerd 1997; Harlou, 2006; Bask et. al. 2010; Simpson et. al. 2014). However, it must be pointed out that no universal consensus exists regarding a conclusive definition of how modular product platforms and architectures should be perceived, nor what defines the related benefits (Bask et al. 2010). It is rare to see the potential of the methodology utilised for service delivery (Voss \& Hsuan 2009) and research in the area of service platform architecture is generally limited (Bask et al. 2010).

Development of an understanding of the concept has been defined as one of the challenges for service innovation and service science (Menor et al. 2002). Pekkarinen \& Ulkuniemi (2008) emphasise the importance of standardisation of services and processes, due to the potential efficiency gains and point out that 
the conceptual benefits are the reasons why modularity related to service innovation and delivery deserves further research attention. Through the presentation of a suggested conceptual model, including elements entitled Service Architecture Layout; Market Segmentation; and Service Roadmap, this paper seeks to improve the understanding of how platforms and architectures based on standardised service modules can support new service innovation and effective service delivery.

Firstly, relevant literature is reviewed to create the foundation for the presented approach and a model for modular service design synthesis. Then we define a number of criteria for successful service platform and architecture development, before continuing to present the conceptual model. Finally, a case study is presented in which the conceptual model has been applied. The case study is used as a basis for discussion and evaluation of the applicability of the model.

\section{Research approach}

Our research generally has an exploratory and qualitative nature. We have strived to apply a synthesis focus, where methodology known from the manufacturing industry, combined with the non-technical elements of services, defines the basis for our research contribution (Carborg et. al. 2014). Industrial insights obtained through engagement with service-based companies created the starting point for our interest in the field of service modularity. We saw a need for structuring and standardising service delivery and innovation to increase competitiveness. Based on our knowledge in the field of product modularity, we started looking into existing literature within the field of service platforms and architectures. Building on the existing research and gaps identified within the field, we started working on a conceptual model for modular service design synthesis. The elements in the model were then tested and evaluated through a comprehensive case study.

The empirical evaluation is based on semi-structured interviews and workshops in a global high-end engineering consultancy, with more than 500 employees. The activities related to introducing and testing our suggested model ran over a period of 6 months. During this period we spent more than 40 days 
physically located in the company, working alongside the technical consultants, observing and getting to know the company from the inside. The objective was to obtain a necessary level of insight, making it possible through the theoretical lens of platform and architecture methodology, to define a structural and functional description of how modular service design synthesis could support operations in the company. Interviews were held with both junior and senior consultants related to 11 specific projects. Workshops were held with senior management to continuously evaluate the conceptual model. Furthermore, historical project data from the past 5 years were studied and evaluated, in order to create a holistic picture of the service delivery process, i.e. timeframes, margins, tasks, service variations etc. and to built an understanding of the different market segment in which the company offered its services. We also identified trends in service innovation and delivery within the company. This allowed us to develop and present a conceptual model, consolidated within the company context. We were furthermore able to evaluate our initial conceptual model and discuss the potential for support service-based companies in structuring and standardising service offerings.

\section{Review of existing literature}

Looking at existing literature framed our work towards presenting a conceptual model for modular service design synthesis. The following chapter of this paper highlights elements, which created the basis for the model.

\subsection{Product platforms and architectures}

A product architecture can be seen as a building principle or blueprint for a product and can be considered as the arrangement of a product's functional elements into a number of physical building blocks. The product architecture also includes a definition of the interfaces between interacting physical elements (Voss \& Hsuan 2009). In classic production-based companies, developing single products one-at-a-time, is costly and ultimately results in a very high number of unique designs. Starting from zero every time that a development process is initiated can increase time-to-market and unique designs can often be seen in products, where using a standardised solution could have saved resources and 
significantly reduced development time (Simpson et. al. 2014; Harlou 2006; Meyer \& Lehnerd 1997).

Designing and leveraging from robust product platforms, from which several product variants can be developed, will give an organisation the foundation to execute multi-product plans, focused on strategic market differentiation (Simpson et al. 2014). It can potentially reduce time-to-market, by supporting rapid product and production development (Meyer \& Lehnerd 1997). Generally the benefits of product platforms and architectures can be found in the dimensions of rationalisation and innovation. Rationalisation focuses on benefits related to the optimisation of the existing business e.g. increased standardisation and effectiveness in production. The innovative dimension focuses on the future of the business, e.g. improved ability to reach out to new markets, rapid new product development based on a reuse of standard designs and leverage of core technologies in new business areas (Meyer \& Lehnerd 1997).

\subsection{A service business must be agile, flexible, and prepared for growth}

The service sector is growing, with global predictions that the $21^{\text {st }}$ century will see both economic and job growth being dominated by this sector (Chae 2012; Chesbrough 2011; Menor et al. 2002). This predicted growth makes it interesting to investigate how service organisations can leverage from the concept of modular platforms and service architectures to effectively handle innovation and service delivery, without being inhibited by increasing portfolio complexity. However, despite its importance, research in the field of alignment between service innovation and service strategy for service-based companies is relatively sparse (Lightfoot \& Gebauer 2011). Implementation of a modular approach to service innovation is assumed to support this alignment and help service-based companies to succeed in effective service innovation.

Voss and Hsuan (2009) argue that the dynamics of the service market generally make it difficult for companies to sustain a competitive advantage. Thus, a service-based company must be agile, flexible and ready to handle growth to become and stay successful and at the same time be able to deliver cost-effective services, without compromising quality and consistency (Menor et al. 2002; Nijssen et al. 2006). This defines the challenge for service businesses to 
manage both customisation and standardisation (Birkinshaw \& Gibson 2004; Chesbrough 2011; Kostopoulos et al 2012). We argue that service-based companies, maybe even more than production-based companies, must be ready to implement radical changes with high frequency and short lead-time in order to sustain success. We believe that by leveraging from modular service platforms, based on a high level of standardisation, it is possible for servicebased companies to move forward at a high pace and obtain the flexibility and scalability needed for success in the service market.

\subsection{Services as a heterogeneous combination of elements}

In contrast to physical products, services are generally intangible in nature and can be defined as activities produced by people, processes and/or systems (Meyer \& DeTore 2001). Services can be seen as heterogeneous constellations with the characteristics of being produced and consumed at the same time and having a process-like nature, which unfolds over a period of time in a specific context (Perrey \& Lycett 2003; Vargo \& Lusch 2011; Bask et al. 2010; Voss \& Hsuan 2009). As an example, a professional consultancy service can be seen as a series of events, occurring between business partners, agreements, deadlines and deliverables. The service has a defined timeframe, with a logical initiation and completion and the service will only create value when delivered in a welldefined context. One aspect that clearly distinguishes services from physical products is the role and influence that people have in the delivery process (Voss \& Hsuan 2009). A service is a co-creation between customer and service provider and generally exists in the boundary between the customer value proposition and implementation (Perrey \& Lycett 2003). As a result of the nature of services, a model for modular service design synthesis must be able to handle this heterogeneity.

The intangible and co-creative nature of services means that a high level of customisation is often part of the service delivery process. This can result in difficulties in standardising service offerings without compromising the ability to satisfy customer needs (Anderson et. al. 1997). This presents a challenge for how to approach modularisation without compromising the competitiveness of a service-based company. The nature of services also makes it relatively difficult to 
define service variants and to specifically identify the building blocks of a service. However, it is possible to identify an understanding that a service can be divided into smaller entities, from which it is possible to define service modules with individual functionalities (Pekkarinen \& Ulkuniemi 2008; Voss \& Husan 2009). In this paper we consider service elements as the smallest entities into which a service can be divided and the combination of these elements into functional units as the basis for modular service development.

Service and product innovation hold many similar characteristics (Nijssen et al. 2006). We argue that translating parts of the methodology for product platform and architecture development to fit service innovation is possible. However, fundamental characteristics of services define a need for adapting the methodology to the service domain. We identify differences in the definition of interfaces and modules. Furthermore, the characteristics of services present a challenge in maintaining stability of potential standardised service offerings. When considering products, modules and related physical interfaces can be defined by a clear specification of functionality, dimensions, material, frequency etc. Service interfaces and service modules may generally have a more heterogeneous nature. The conceptual model presented in this paper will strive to improve the understanding of how service interfaces and modules can be constructed and visualised, to support modular service design synthesis.

\subsection{Service platforms and architectures}

Research in the field of service modularity and service architecture development is generally limited (Pekkarinen \& Ulkuniemi 2008; Bask et al. 2010). Sundbo (1994) was one of the first to investigate how modularisation can support service innovation, since then publications concerning similar fields of research have followed. Notable publications include Menor et al. (2002), Meyer \& DeTore (1999, 2001), Pekkarinen \& Ulkuniemi (2008), Voss \& Hsuan (2009) and Bask et al. (2010). More than ten years ago, Menor et al. (2002) defined the field as an important area for service innovation. Integrating modularity and architectural thinking into service innovation and delivery has since been gaining increased attention (Voss \& Hsuan 2009). 
Voss and Hsuan (2009) define areas within the framework of service architecture and modularity that can support the competitiveness of servicebased companies. They argue that applying a modular structure to service innovation and delivery will make it difficult for competitors to copy service offerings and that the ability to leverage from modularity, through reuse, will reduce time-to-market, support customisation and help service-based companies to sustain competitive advantages. Generally the ability to leverage from existing assets to fast and efficiently deliver and launch new service offerings is seen as one of the strongest benefits related to service modularity (Crawford et al. 2005; Meyer \& DeTore 2001; Voss \& Hsuan 2009).

Tuunanen et al. (2012) define three concepts of service modularisation. They argue that for service-based companies to benefit from modularity and standardisation, they have to work within the dimensions of service modules, service architecture and service experience. The service modules make up the service architecture and together they constitute the service experience. Looking at service modularity, Pekkarinen \& Ulkuniemi (2008) generally describe a service module as an integration of various functions within a company and Homann et al. (2004) adds that each service module should hold a high degree of autonomy. Blok et al. (2010) provide a description of three kinds of service modules: basic modules, common to all services; modules that can be configured to accommodate specific needs; and modules used for customisation of the individual services. It is, however, still unclear how service modules are designed. The general understanding of this paper, is that it is possible to identify service building blocks i.e. service elements, which can be combined into subsystems, each holding a specific functionality and which, when put together, constitute the service (Bask et al. 2010). One of the requisites for working with modularisation and standardisation is the ability to define stable modular interfaces. However, it is generally difficult to find a unified view of dimensions included in modular service interfaces. As similar to product modularity, interfaces are generally considered of high importance for the success of a modular service architecture (Voss \& Hsuan 2009). As Lin et. al. (2015) highlight, the definition and application of interfaces within the domain of service dominant logic, holds a potential for optimising business operations. They define 
three different types of interfaces: design-; process-; and information interfaces. Voss and Hsuan (2009) describe interfaces between subsystems in a service architectures, as containing the dimensions of people, information and rules, which governs the flow of information. It is also possible to distinguish between modular interfaces and customer interfaces (Bask et al. 2010). Generally we see interfaces within the domain of services holding different dimensions with a heterogeneous nature.

Meyer \& DeTore (1999) and Pekkarinen \& Ulkuniemi (2008) have presented models with similarities to the conceptual model (figure 2). Meyer and DeTore (1999) apply a product development framework to service development and define a model consisting of three dimensions: the market segmentation grid; production platform; and core competencies. They emphasise the importance of integrating market considerations related to modular service development, to define market segmentations and clearly focus service development. The production platform includes modules or subsystems connected by interfaces, which by mix-and-matching can accommodate the identified customer needs. The final dimension focuses on the core competences within the company and how these can be developed to support the modular production platform. Pekkarinen \& Ulkuniemi (2008) go deeper into the development of the modular service platform, and define three levels of modularity: modular service offerings; modular organisation; and modular processes, where interfaces exist between the different levels of modularity. With respect to these two rather similar models, it appears that there is room for improvement regarding the understanding of how to design service platforms to support clear strategic service delivery and innovation.

The existing literature in the field of service modularity and architecture development generally agrees that benefits exist similar to what is seen for product modularity and architecture development, i.e. reduction in cost and time-to-market for new service innovations and increased flexibility. However, the literature leaves room for improvement regarding the understanding of how to approach modular service development. Generally, the process of service innovation can be said to be rapid and dominantly incremental in nature (Hipp \& Grupp 2005), which makes it interesting to improve the understanding of how a 
service company can leverage from modular development through strategic planning and define a healthy balance between service standardisation and customisation. Based on the review of literature it is proposed that aspects concerning definition of elements and key interfaces in a service architecture leave room for further improvement. This creates the basis for introducing a model for modular service design synthesis, as is proposed in this paper. Due to the heterogeneous and intangible nature of services, an important function of the presented model is to give a simple and visual representation of how modules can be deployed to support modular service offerings (Mortensen et al. 2008).

\subsection{Criteria for service platform development}

Criteria for successful service innovation can be found in the literature. Tan et al. (2009) define a number of steps that a company should consider to successfully integrate services into their portfolio. One is being able to design a well-defined service platform that can secure effective delivery of services and improve productivity by automation, standardisation or delegation of activities and responsibilities. Lightfoot \& Gebauer (2011) and Droege et al. (2009) agree that successful service innovation for business practice must include dimensions of service, market and strategy related factors. Furthermore, Droege et al. (2009) define the need for active management of human resources, if a service-based company is to succeed in radical service innovation.

As identified, a critical aspect for service modularisation is to be able to align activities and decisions across different domains i.e. market related decisions, decisions related to human resources and strategy for innovation. We believe this is possible by addressing the overall dimensions of flexibility, scalability, standardisation and competitiveness. To support these aspects the conceptual model should be able to accommodate a number or criteria displayed in the specification seen in figure 1 . The specification is summarised from the findings in literature and the needs identified in industry. 


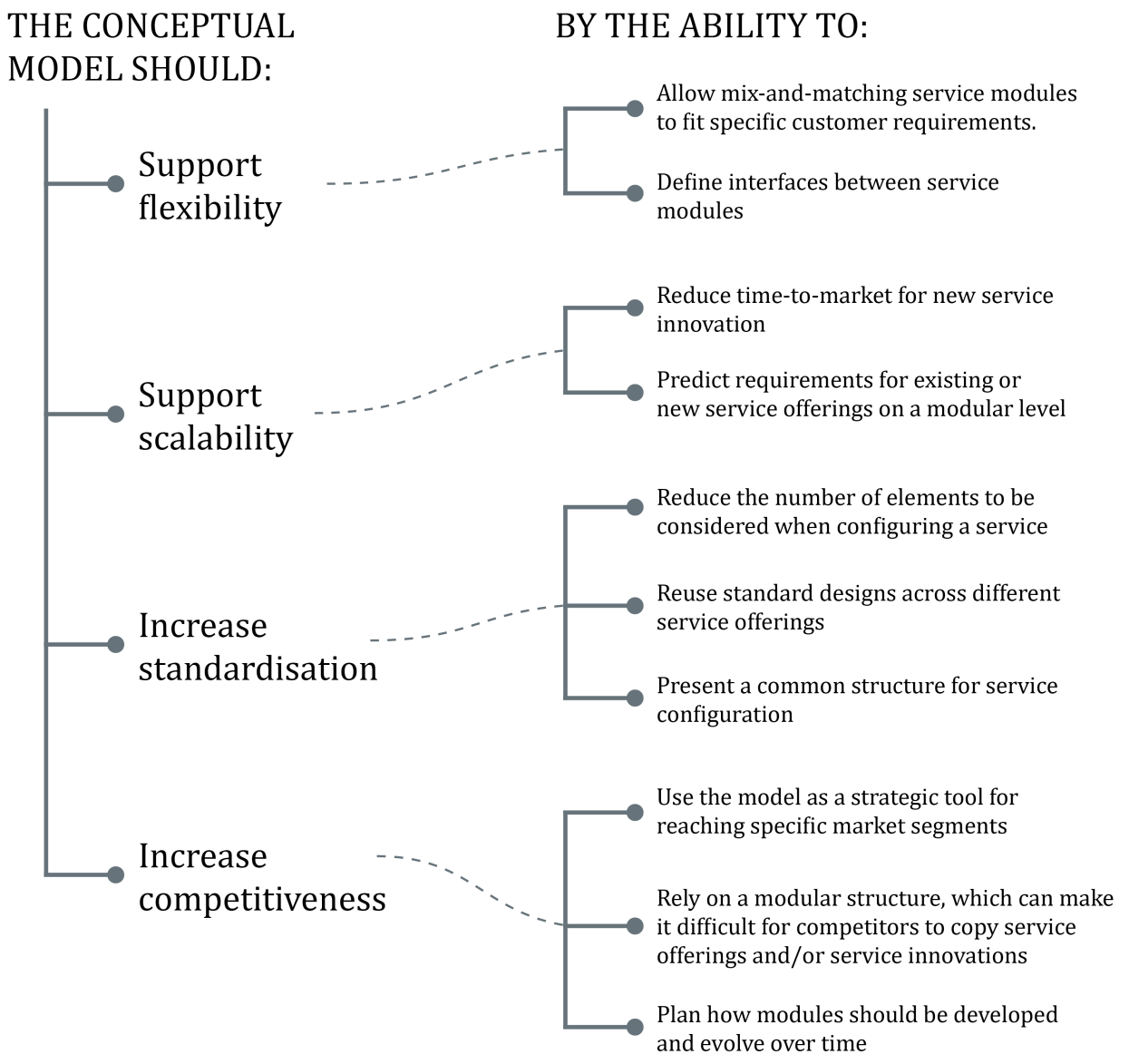

Fig 1 Specification for conceptual model

\section{Conceptual model}

The following describes our proposed conceptual model for service platform and architecture development. The model is presented in a number of figures, which capture the concept. We highlight the importance of defining a clear strategy for modular service design synthesis, which we suggest should include market considerations, a service architecture structure and a planning dimension i.e. road-mapping. The concept outline of our model presented in figure 2 visualises how these dimensions are integrated to form the frame for developing modular service platforms, including the Market Segmentation, the Service Roadmap and the Service Architecture Layout. 


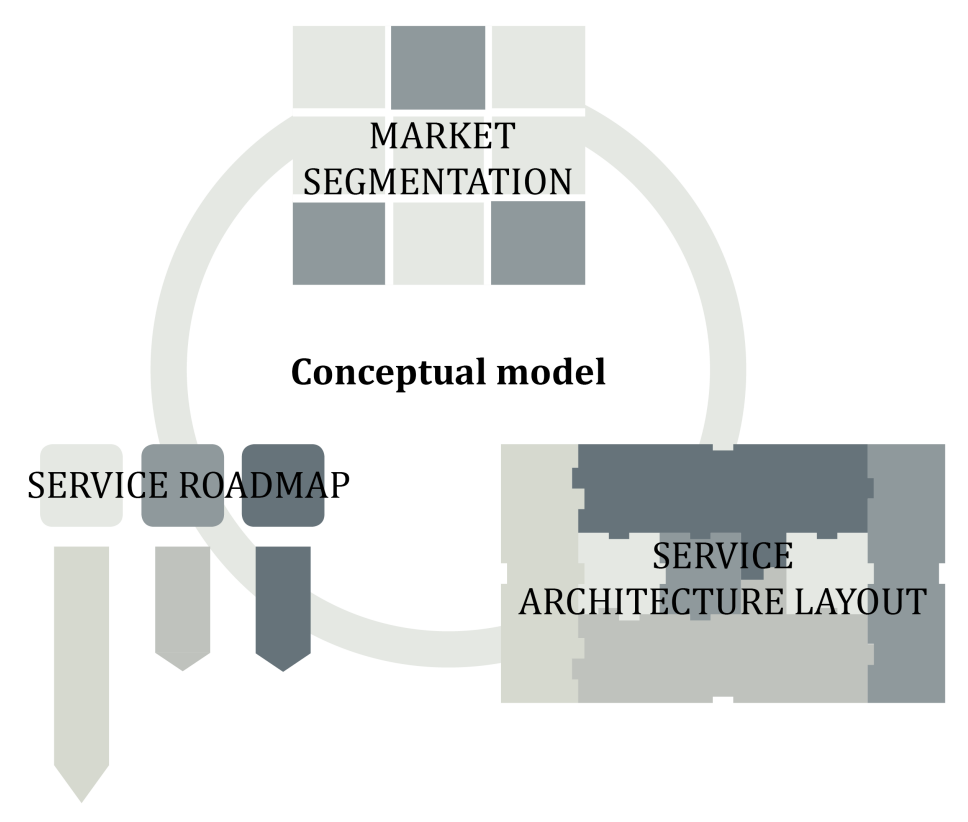

Fig 2 Dimensions of the conceptual model

Existing literature has created the basis for the model (Meyer \& Lehnerd 1997; Meyer \& DeTore 1999; Harlou 2006; Pekkarinen \& Ulkuniemi 2008). We add to the current understanding of modular service design synthesis by connecting these elements and introducing the Service Architecture Layout. This will allow alignment between modular service delivery and innovation, which we consider one of the keys to succeed with modular service development.

\subsection{The Market Segmentation}

The market segmentation is considered an essential dimension for modular service delivery and innovation. It allows identifying focus for service platform development as it helps to strategically aim service offerings. The presented model (figure 3) is deduced from the power tower and market segmentation grid presented by Meyer \& Lehnerd (1997). Meyer \& Lehnerd (1997) present the power tower in the context of product platform and architecture development, in order to show how platform development can be used as a strategic tool. Later they apply the same approach to services and argue that they are able to translate the methodology from products to services (Meyer \& Lehnerd 1999). Pekkarinen \& Ulkuniemi (2008) also introduce market segmentation in their conceptual model for modular service development. We believe that this approach is essential for applying service modularity to strengthen 
competativeness for service-based companies and to allow strategic decisions related to defining core business areas, portential extensions and new market entries. We propose an evaluation of each market segment based on attractiveness, competition and predicted market development. Figure 3 shows a generic representation of a market segmentation where different market segments; A, B and C are found on the horizontal axis, each representing different customer demands. On the vertical axis different performance levels are found e.g. low-end, mid-range and high-end segments. Focusing on performance scaling gives service-based companies the possibility to define standardised off-the-shelf service solutions focused on performance level 1 and then scaling up performance through integration of additional features. We argue that this type of segmentation will give a strong foundation for the definition of a strategic focus for a service platform.

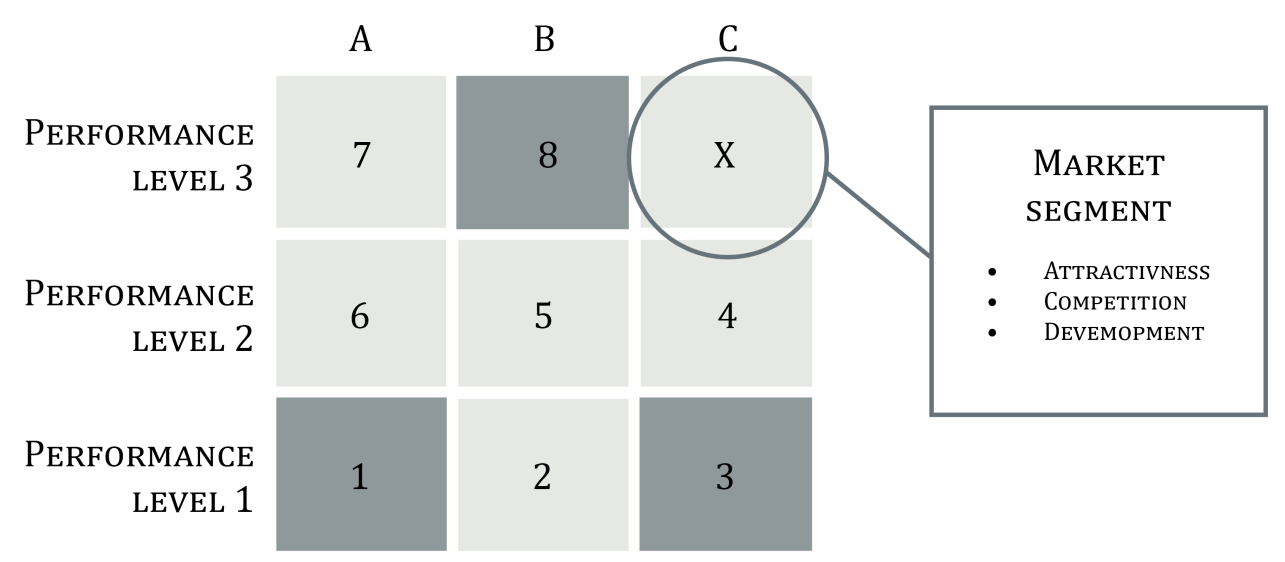

Fig 3 Market segmentation

\subsection{Service roadmap}

Strategy related to approaching different market segments is closely connected to the roadmap dimension. The Service Roadmap indicates how to approach new market segments by upgrading or introducing new modules into a service platform. We base our understanding of how to model and visualise the service roadmap on the examples found in Harlou (2006). The ability to clearly define a roadmap with focus on modular development is one of the major benefits of modular service development. The roadmap dimension allows a definition of how each subsystem can gradually be improved and how integration of new 
innovations and technology can be handled. The stability of the interfaces between each subsystem in the Service Architecture Layout is of high importance and allows the modules to be upgraded or replaced, without affecting other parts of the service architecture. This allows managing each service module individually and increases flexibility and adaptability of a service-based company. Figure 4 shows an example of how development of the individual subsystems can be managed to reach new benchmarks e.g. service upgrade to version 2.0 or preparing to enter a new market segment.

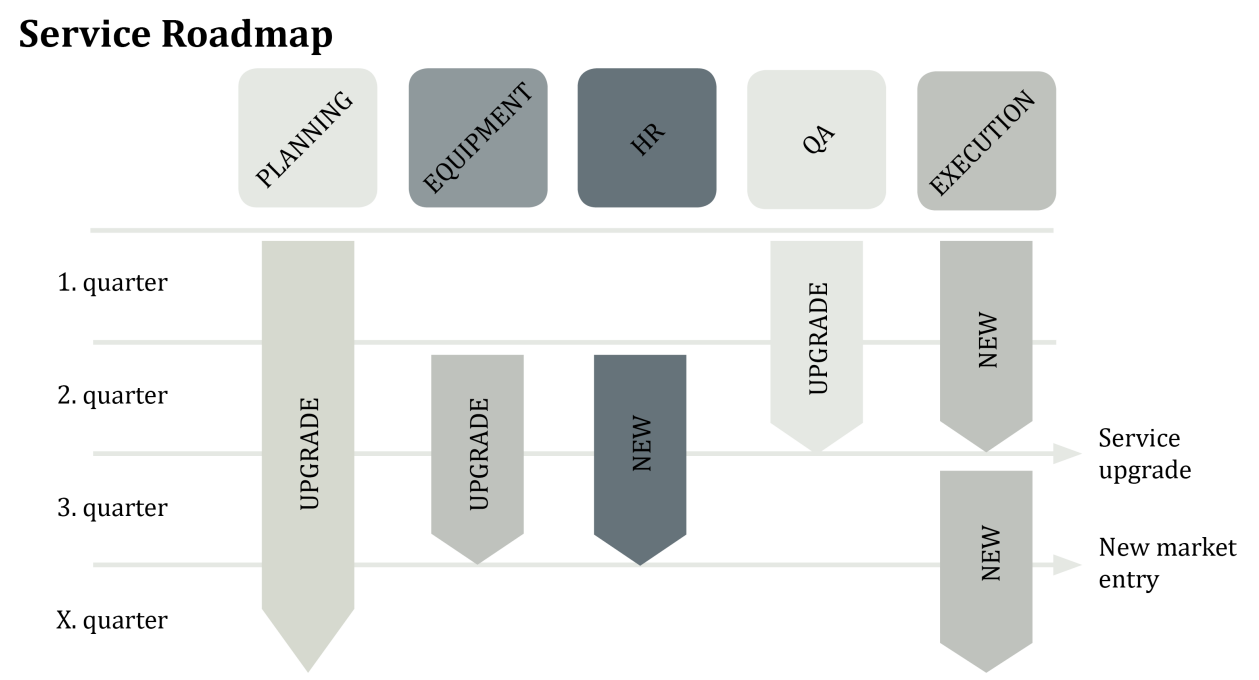

Fig 4 Example of service roadmap

\subsection{The service architecture layout}

The architecture layout describes our proposed principle for structuring services and defines the basis for modular service development and delivery. It includes description of service modules, interfaces and add-ons. Existing research within functional modelling (Harlou 2006) has inspired the representation of the Service Architecture Layout. The purpose of the model is to present the functional elements/modules needed to constitute a service and the interrelations/interfaces between these modules. In the Service Architecture Layout the functional modules are represented as boxes with an attached attribute e.g. Execution or Planning and interfaces are represented as "plugs and sockets" between these boxes. 


\section{Service Architecture Layout}
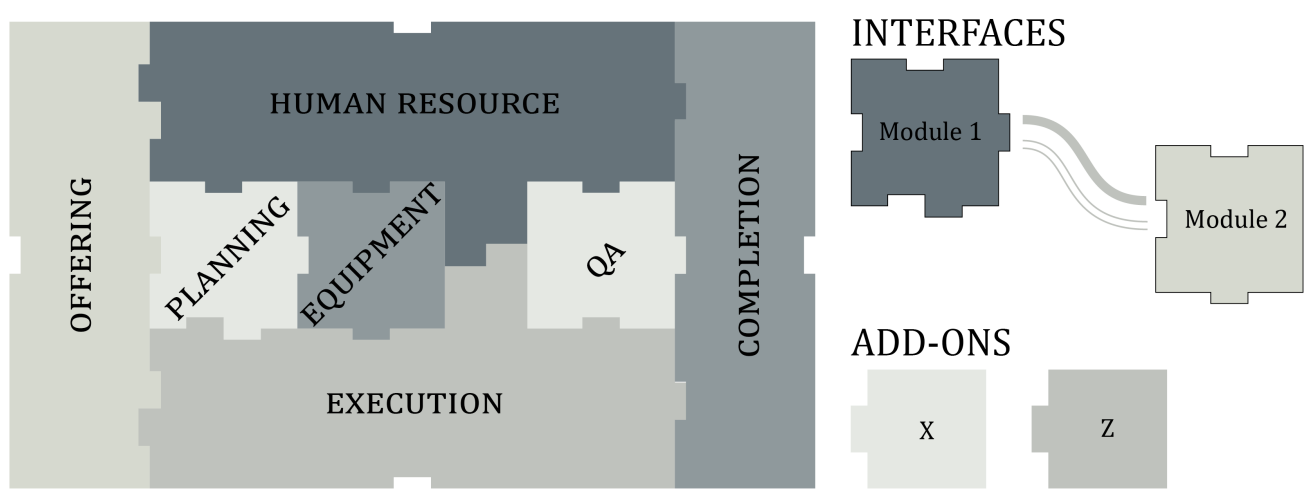

ADD-ONS

$\mathrm{x}$

Z

Fig 5 The Service Architecture Layout

\subsubsection{Modules}

Seven generic subsystems: Offering; Planning; Equipment; Human Resources; Execution; Quality Assurance; and Completion, each with a specific functionality, constitute the Service Architecture Layout (figure 5). The modules are generic representations and must be designed to specifically fit the service context in which the model is implemented. Each module in the Service Architecture Layout holds a functionality and when combined, they constitute the service offering. Each module can have a number of standard designs. It is these standard designs that constitute the service platform. As example, difference instances of the module Human Resources could be e.g. junior consultant, senior consultant and chief consultant and describe the specific competencies for each performance step. When configuring a service and determining the requirements for a specific service offering, the best suited standard design for Human Resources can be selected. The required input for selection is provided through the interfaces between the Human Resource module and the other modules in the Service Architecture Layout.

\subsubsection{Interfaces}

As identified in existing literature, interfaces related to service modularity are described with a heterogeneous nature. We have translated this into an interface definition in the dimensions of dependencies and artefacts. The artefact dimension describes tangible elements needed for two modules to interconnect e.g. reports, plans/guidelines or instruments/tools. The dependencies describe the demands and requirements of an interconnection between two modules e.g. 
demand for specific human resources, capabilities or other modular characteristics.

\subsubsection{Add-ons}

Add-on features are individual autonomous entities with separate specification. Each has an external interface, which allows connection to the core of the architecture framework. The autonomous add-on features are considered necessary to increase flexibility and accommodate customisation in a service platform.

\section{Example of application}

To give an example of how the suggested model can be applied, we imagine the fictive service-based company 'Cleaning Inc.'. Based on the 'cleaning platform 1', Cleaning Inc. provides services for the different market segments illustrated in figure 6.

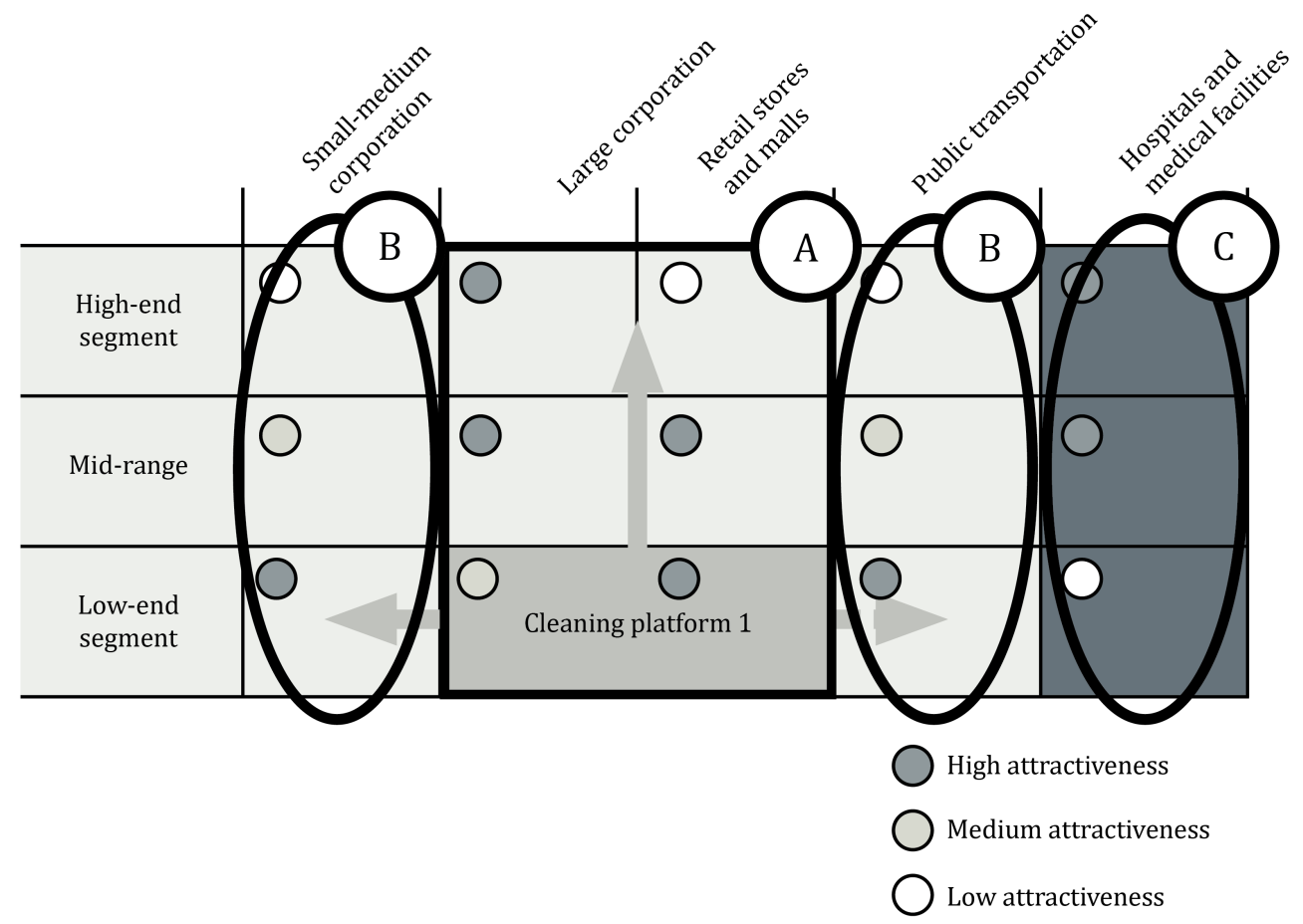

Fig 6 Market segmentation for Cleaning Inc.

Scaling of performance allows vertical leverage of the service platform to reach both the mid-range and high-end market segments. When looking ahead, 
Cleaning Platform 1 can be extended horizontally to reach out to new market segments (Meyer \& Lehnerd 1997). In figure 6, Segment A defines the core focus for Cleaning platform 1 and the B segments illustrate market opportunities, thought to be reachable through update of the existing platform. Segment $\mathrm{C}$ illustrates a potential market, reachable through major updates or introduction of a new service platform. Figure 7 shows how the Service Architecture Layout is used to structure standard designs from the Cleaning Platform 1 into modular service offerings. 


\section{Cleaning Platform 1}
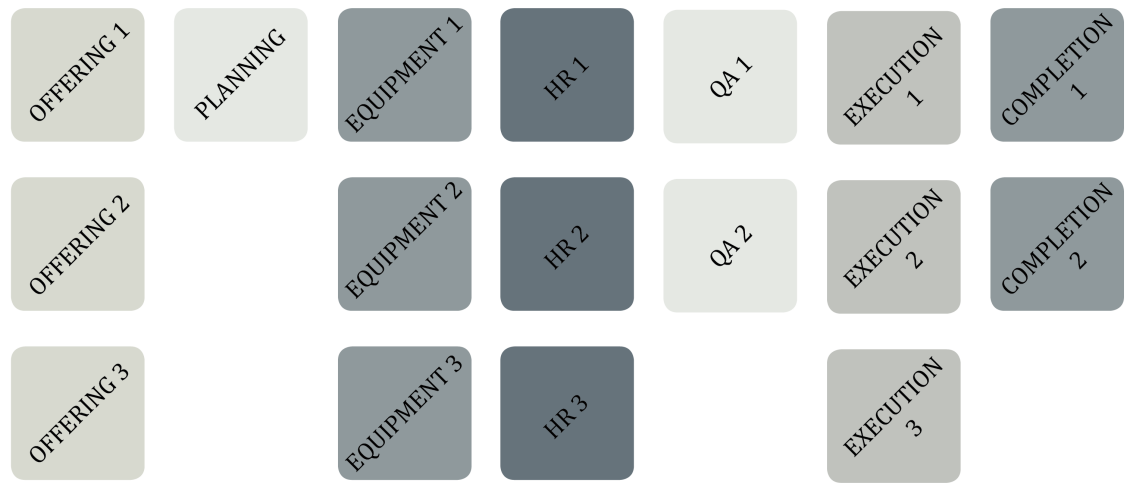

\section{Service Architecture Layout}

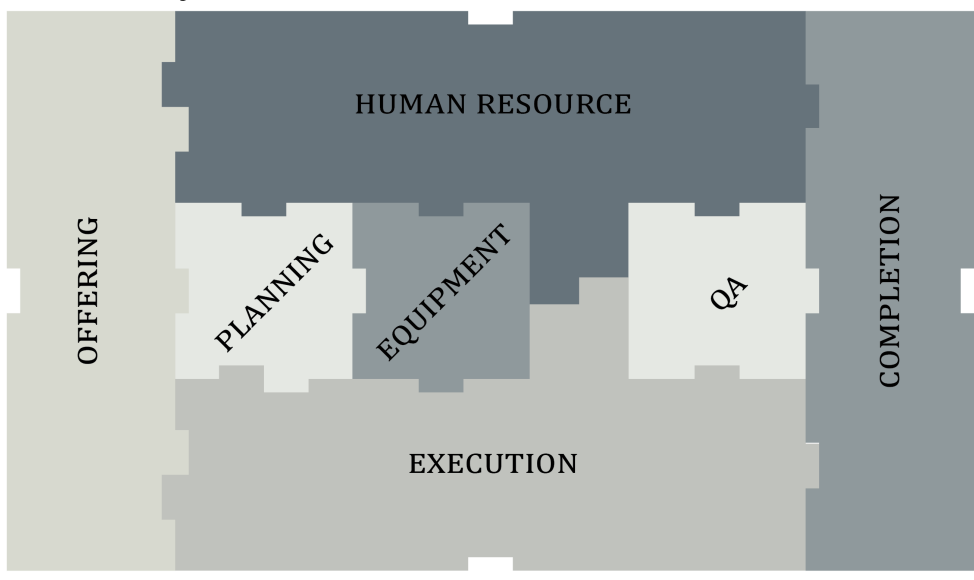

\section{Service Offerings}
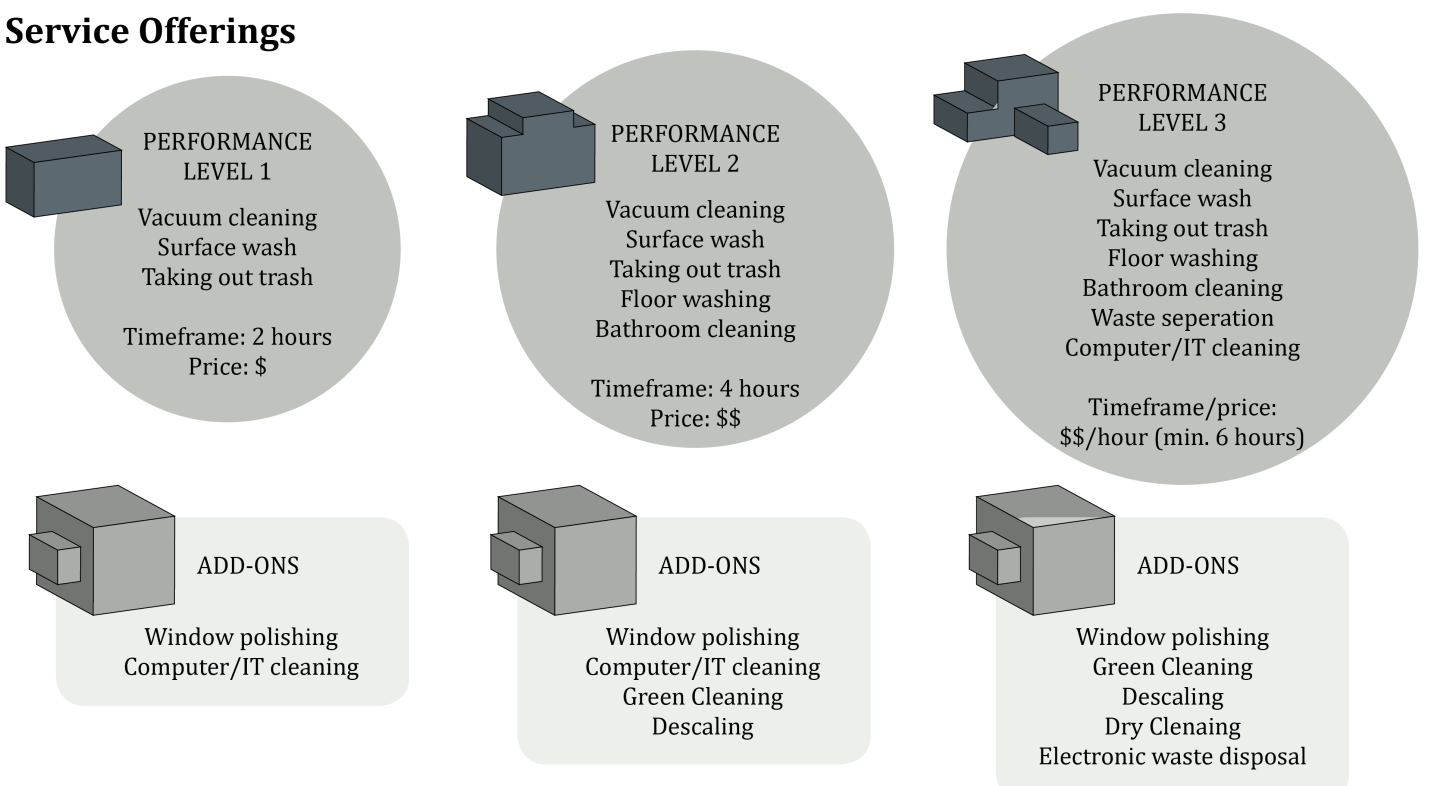

Fig 7 Service delivery based on Cleaning Platform 1 
As indicated in figure 6, Cleaning Inc. desires to focus on two new market segments (B segments). In this example, an update and extension of the Cleaning Platform 1 is expected to enable this. On a modular level the service roadmap (figure 4) defines how each module should be upgraded to reach out to the new segments and when introduction of new subsystems is necessary.

To evaluate the model against the specification (figure 1), we applied it in a context where service delivery and innovation were not based on a modular strategy.

\section{Empirical study of service delivery and innovation based on the conceptual model}

A case study in a leading global high-end engineering consultancy has created the basis for evaluation of our suggested model for modular service design synthesis. The case company mainly operates with service offerings in the maritime and energy sectors and were, at the time for our study, facing challenges related to profitability and consistency in their service delivery process. Furthermore, the company had experienced difficulties in leveraging core technologies from one business area to another, hereby losing potential highly valuable business opportunities. This created the basis for an operational test of the model in an effort to increase consistency in the service delivery process and increase organisational flexibility.

The scope for platform development was limited to a single service family, which allowed presenting a specific design within a relative short timeframe. As no previous experience with modular service delivery existed within the company, it was considered of high importance to limit the scope and present a simple and tangible modular design. Focus was placed on services related to commissioning of new or revamped compressors installed in oil and gas facilities. This service family had historically presented a number of challenges, which made them difficult to handle and made it difficult to maintain consistency in the service delivery process. Eleven historical projects were selected in collaboration with the case company and these served as basis for understanding the service delivery process. The projects were analysed to 
identify commonality across services, which created the basis for combining service elements into service modules. From decomposition of services and integration of service elements, it was possible to define modules, add-ons and key interfaces and to present the Performance Platform. This platform was focused on service delivery at three performance levels. Examples of service elements combined to form modules were e.g. tools, analysis methods, measurements methods and technical capabilities.

It was possible to identify a positive market development in the segment of commissioning, as investments in the energy sector and rising global energy demands were expected to generate new business opportunities related to construction of new oil and gas installations. This trend made it interesting to define a platform, where leveraging from modular standard designs could support service delivery. The Market Segmentation was used to visualise this trend and to identify the core focus for the Performance Platform and identify where market development was expected. Through the Service Roadmap we were able to indicate which modules should be updated over a period of four years to accommodate the evolving customer needs. The identification of commonality between services allowed definition of standard designs. Together with market alignment and a plan for service updates, it was possible to present a modular approach to service delivery and innovation.

\subsection{Introducing the Performance Platform}

The Performance Platform included 22 different standards designs and 25 addon features. Through mix-and-matching of these modules and add-ons, a high number of service variants were supported at three performance levels. Performance level 1 focused on off-the-shelf service delivery and was considered the smallest saleable unit of commissioning. The scope of a service included structural assessment of the compressor and the services required limited instruments, experience and hours on-site. The service was design so that an inexperienced consultant with limited capabilities could perform it. The possibility for customisation at performance level 1 was relatively limited. On top of the structural assessment, service delivery at performance level 2 included a contextual assessment e.g. influence of foundation, other machinery linked to 
the compressor and compressor casing. Service delivery at performance level 2 had higher requirements to the involved consultants, as integration of external instruments to perform measurements was needed. The last performance level represented the most comprehensive packages and included the scope of services at both performance level 1 and 2 and furthermore focused on the process within the compressor e.g. temperature, mass flow and pressure. Assessing the internal processes in a compressor requires experience and extensive capabilities from the involved consultants. At level 2 and 3 the possibility for customisation through additional standard designs and integration of add-ons increased.

An example of a standard design, included in the Performance Platform, is the execution module aimed at the basic low-end segment. This included definition of an approach for Base Line Vibration Measurements on the compressor train. As seen in the Service Architecture Layout this module interfaced with the human resource and planning modules. The interface between execution and human resources defined a need for specific competences and a timeframe for execution. The planning interface defined a need for tools, measurement plan and definition of service context e.g. onshore or offshore service delivery. Add-ons were defined, where low commonality existed between services. As example, an add-on for Valve Response Time verification was defined, including description of tasks to be performed, timeframe, and cost. It interfaced with the execution module by defining competence requirements and tools needed.

Introducing the Performance Platform allowed for standardised subsystems to be reused for several service offerings related to the service family of Commissioning. To evaluate service standardisation we compared the original number of elements included in the 11 service offerings we analysed, with the number of defined modules in the Performance Platform. By doing this, we are able to argue that instead of starting from zero every time a service should be configured and with high degree of freedom in the configuration process. We were now able to present a limited number of standard designs and add-on features, which could be reused and combined into service offerings, while serving the same market segments. This allowed increasing 
standardisation of service offerings by as much as 56\%. With the design of the Performance Platform it became possible to change focus from individual service development to service development on a modular level. Market predictions made it possible to strategically plan future upgrades and integration of new standard designs to reach new market segments. The ability to mix-and-match standard designs supported the ability to leverage from core technologies and competences in one area to another e.g. measurements, analysis and approach for verifying structural vibrations in a compressor could be translated to fit verification of vibrations in safety structures in high-speed trains. Finally, the standardised back-end was believed to support an improved cost-efficiency for service delivery. In the configuration process mix-and-matching services based on the Performance Platform would indicate the needed timeframe and competence level for a service, thus enabling a standardised cost structure for all services. As we saw in the case company, this could remove the challenge for cost estimation of a customised service offering, where the individual service provider, with a very high degree of freedom and in a co-creative environment, had to evaluate the price setting.

\section{Evaluation of the conceptual model}

Developing a service platform based on the conceptual model and introducing it in the case company have shown potential for supporting the service delivery and innovation process. Potentials can be found in both the dimension of rationalisation of the existing service portfolio and in the dimension of improved innovative potential. The conceptual model was based on a synthesis focus, where methodology from the world of physical product development were combined and altered with the unique characteristics of services to fit a service context. This is seen in the definition of service modules and interfaces e.g. by defining interfaces in the intangible dimension of dependencies and the physical dimension of artefacts. The findings we present indicate that the conceptual model is able to live up to the specification defined in figure 1 and that a potential exist for working towards a holistic framework for modular service design synthesis. 
The nature of services makes it difficult to identify and distinguish commercial variants and due to the high level of co-creation it can be argued that close to infinite service variants exist. Blok et al., (2010) argue that this can limit the possibility for repetitive execution of service components and might limit the possibility for advantages in efficiency. This defines a fundamental challenging for modular service development. The conceptual model can potentially support service-based companies in defining this difficult trade-off between standardisation.

The Market Segmentation and Service Roadmap are elements with similarities to what have see in existing research (Meyer \& Lehnerd 1999; Harlou 2996; Pekkarinen \& Ulkuniemi 2008). Inclusion of these two elements in the conceptual model supports the critical alignment of strategy, execution and innovation in service operations. We believe this is key to strengthening competitiveness and to achieving the identified potential benefits related to service modularity. The Service Architecture Layout represents a supposed generic building principle for modular services. This principle allows a servicebased company to identify standard designs and interfaces for each module and is key to the process of standardising service offerings. The proposed structure of the Service Architecture Layout was successfully able to accommodate service offerings and the configuration process in the case company. As this has only been verified in one case, other ways may exist to represent this structure, e.g. by adding or changing modules and/or interfaces. However, we consider the definition of a common service architecture as the starting point for service standardisation. The ability to built service offerings based on a standardised structure is the basis for increasing flexibility by allowing a level of mix-andmatching the standard design and add-on features.

As the goal for our research has been to present and test a conceptual model for modular service design synthesis, we have not addressed the dimension of governance and organisation of modular service delivery and innovation. Further research should be put into this aspect to investigate how service modularity should be controlled and maintained. The evaluation of the conceptual model is based on a single case study and further research should focus on a validation of the presented approach and a broader generalisation of 
our findings. Challenges related to definition of service variants and in securing stability and robustness of a service architecture have been identified. Our findings related to the development and introduction of the Performance Platform in the case company are highly qualitative. We see a large potential in focusing further research on quantifying these findings and give a specific answer to e.g. decrease in time-to-market and increase in innovative potential.

\section{Concluding remarks}

The presented case study showed how an engineering consultancy, through reuse of well-defined standardised subsystems, i.e. service modules, could potentially improve their service delivery process. Furthermore, through definition of the Performance Platform, the presented model enables working with service design synthesis and updates on a modular level, thus simplifying the process of adjusting the service portfolio. With a clear focus for platform development including the elements presented in the conceptual model, it was possible to define functional units within service families and identify a level of commonality between service variants, thus developing service modules aimed at strategic market segments.

The conceptual model defines a holistic approach to modular service development and includes the three dimensions of Market Segmentation, Service Architecture Layout, and strategic planning through Road Mapping. We believe that developing a robust platform as foundation for service innovation and delivery can be a key for service-based companies to increase flexibility and enable efficient strategic execution of service delivery and innovation. Generally, the identified potential benefits of service delivery and innovation based on modular service platforms, i.e. increased flexibility; cost efficiency; service consistency; and reduction in time-to-market, align well with the challenges identified for service-based companies today, i.e. changing market structures; short service life cycles; and increasing competition.

We believe that the conceptual model presented in this paper provides a meaningful contribution to the understanding of how service-based companies could approach modular service delivery and innovation. We hope that the research in this paper will contribute to push forward the emerging topic of 
service modularity.

\section{Acknowledgments}

We would like to acknowledge Philip Schur Rørvig for his major contribution to the collection empirical data, which has created the basis for evaluation of the conceptual model presented in this paper.

\section{References}

Anderson E, Fornell C, Rust R (1997) Customer Satisfaction, Productivity, and Profitability: Differences Between Goods and Services, Marketing Science, 16(2), 129-145.

Bask A, Lipponen M, Rajahonka M, Tinnilä M (2010) The concept of modularity: diffusion from manufacturing to service production, Journal of Manufacturing Technology Management, 21(3), 355-375.

Birkinshaw J, Gibson C (2004) Building Ambidextarity Into an Organization, MIT Sloan Management Review, 45(4), 47-55.

Blok C, Luijkx K, Meijboom B, Schols J (2010) Modular care and service packages for independently living elderly. International Journal of Operations \& Production Management, 30(1), 75-97.

Carlborg P, Kindström D, Kowalkowski C (2014) The evolution of service innovation research: a critical review and synthesis. The Service Industries Journal, 34(5), 373-398.

Chae B (Kevin) (2012) An evolutionary framework for service innovation: Insights of complexity theory for service science. International Journal of Production Economics, 135(2), 813-822.

Chesbrough H (ed.) (2011) Open Services Innovation: Rethinking Your Business to Grow and Compete in a New Era. San Francisco: Jossey-Bass.

Collier D (1981) The Measurement and Operating Benefits of Component Part Commonality, Decision Sciences, 12(1), 85-96.

Crawford CH, Bate GP, Cherbakov L, Holley K, Tsocanos C (2005) Toward an on demand service-oriented architecture. IBM Systems Journal, 44(1), 81-107.

Droege H, Hildebrand D, Forcada MH (2009) Innovation in services: Present findings, and future pathways. Journal of Service Management, 20(2), 131-155.

Harlou U (ed.) (2006) Developing product families based on architectures. Lyngby: Department of Mechanical Engineering, Technical University of Denmark. 
Hipp C, Grupp H (2005) Innovation in the service sector: The demand for service-specific innovation measurement concepts and typologies. Research Policy, 34(4), 517-535.

Kostopoulos G, Gounaris S, Boukis A (2012) Service blueprinting effectiveness: drivers for success, Managing Service Quality, 22(6), 580-591.

Lightfoot H, Gebauer H (2011) Exploring the alignment between service strategy and service innovation, Journal of Service Management, 22(5), 664-683.

Lin Y, Pekkarinen S, Ma S (2015) Service-dominant logic for managing the logistics-manufacturing interface, The International Journal of Logistics Management, 26(1), 195-214.

Menor LJ, Tatikonda MV, Sampson SE (2002) New service development: areas for exploitation and exploration, Journal of Operations Management, 20(2), 135157.

Meyer MH, DeTore A (1999) Product development for services. Academy of Management Perspectives, 13(3), 64-76.

Meyer MH, DeTore A (2001) PERSPECTIVE: Creating a platform-based approach for developing new services. Journal of Product Innovation Management, 18(3), 188-204.

Meyer MH, Lehnerd AP (eds.) (1997) The power of product platforms: Building value and cost leadership. New York: The Free Press

Mortensen NH, Pedersen R, Fiil Nielsen O, Harlou U, Bøgh MH, Høgh PT, Hvam L (2008) Implementing a product platform in 35 man-days: the visual thinking approach, International Journal of Mass Customisation, 2(3/4), 240-263.

Nijssen EJ, Hillebrand B, Vermeulen PAM, Kemp RGM (2006) Exploring product and service innovation similarities and differences. International Journal of Research in Marketing, 23(3), 241-251.

Pekkarinen S, Ulkuniemi P (2008) Modularity in developing business services by platform approach. The International Journal of Logistics Management, 19(1), 84103.

Perrey R, Lycett M (2003) Service-Oriented Architecture. 2003 Symposium on Applications and the Internet Workshops (pp. 116-119).

Simpson T, Jiao J, Siddique Z, Hölttä-Otto K, (2014) Advances in Product Family and Product Platform Design, New York: Springer Science + Business Media.

Tan A, McAloone T, Matzen D (2009) Service-Orientated Strategies for Manufacturing Firms. In Sakao, T. \& Lindahl, M. (eds.) Introduction to Product/Service-System Design. London: Springer 
Tuunanen T, Bask A, Merisalo-Rantanen H, (2012) Typology for Modular Service Design: Review of Litterature, International Journal of Service Science, Management, Engineering, and Technology 3(3), 99-112.

Vargo SL, Lusch RF (2011) It's all B2B...and beyond: Toward a systems perspective of the market. Industrial Marketing Management, 40(2), 181-187.

Voss CA, Hsuan J (2009) Service Architecture and Modularity, Decision Science, $40(3), 541-569$. 